\section{Entrevista: Carmen Teixeira}

Interview: Carmen Teixeira
Resumo Carmen Fontes de Souza Teixeira nasceu na Bahia e, atualmente, exerce o cargo de professora associada do Instituto de Saúde Coletiva, da Universidade Federal da Bahia (UFBA). Participante ativa do movimento da reforma sanitária, em meados dos anos 1970, tem vasta experiência na área de Saúde Coletiva, com ênfase em Saúde Pública, atuando em diversas frentes, com destaque para gestão de sistemas, políticas públicas, organização de serviços, planejamento e desenvolvimento gerencial. A Escola Politécnica de Saúde Joaquim Venâncio, da Fundação Oswaldo Cruz, através do Laboratório de Educação Profissional em Vigilância em Saúde (Lavsa), convidou-a para proferir a palestra "Os sujeitos da Vigilância em Saúde: construindo uma proposta curricular para a formação técnica", no auditório Joaquim Alberto Cardoso de Melo, em 9 de julho de 2007. Neste mesmo dia, Carmen Teixeira concedeu a entrevistal $^{l}$ que se segue. Nela, revive a discussão da mudança do modelo de atenção em saúde e examina temas como a vigilância em saúde enquanto proposta contra-hegemônica a partir da revisão de currículos, subjetividade na formação de profissionais de saúde, intersetorialidade, empoderamento dos agentes de vigilância e muito mais, sempre na perspectiva da Reforma Sanitária e do aperfeiçoamento dos profissionais que atuam no setor.
Abstract Carmen Fontes de Souza Teixeira was born in Bahia, and is now associate professor at the Collective Health Institute of the Federal University of Bahia (UFBA). An active participant in the sanitation reform movement of the mid-'70s, she has vast experience in the area of Collective Health, with an emphasis on Public Health, and acts in various fronts such as systems management, public policies, organization of services, and administrative planning and development. Through the Health Surveillance Professional Education Laboratory (Lavsa), the Joaquim Venâncio Polytechnical Health School, of the Oswaldo Cruz Foundation, invited her to give the lecture "the subjects of Health Surveillance constructing a curricular proposal for technical training and education", at the Joaquim Alberto Cardoso de Melo auditorium, on July 9, 2007. On that same day, Carmen Teixeira granted the interview that follows. In it, she relives the discussion about the change in the health care model and examines themes such as health surveillance as a counter-hegemonic proposal based on the revision of curriculums, subjectivity in the training of health professionals, intersectoriality, empowerment of surveillance agents, and much more, always from the perspective of Sanitation Reform and the improvement of professionals of that sector. 


\section{Revista}

A proposta de Vigilância em Saúde pode ter favorecido, ou pode vir a favorecer, a efetivação dos ideais da Reforma Sanitária?

\section{Carmen Teixeira}

Essa pergunta é muito interessante porque me permite uma viagem no tempo. Todos nós que participamos do movimento da Reforma Sanitária temos de lembrar que o início de toda a discussão, em meados da década de 1970, tinha como enfoque exatamente a mudança do modelo de atenção, logo que começou a crítica à medicina preventiva, feita por Sergio Arouca, e a discussão sobre as práticas de saúde, por Cecília Donnangelo. O ponto de partida de todo o movimento da reforma era exatamente uma análise crítica da prática médica, do que hoje entendemos como modelo médico hegemônico, modelo médico assistencial, hospitalocêntrico. Embutida nessa preocupação estava a busca de alternativas, as quais, na época, se apresentavam como a própria medicina preventiva, como uma forma de introduzir a questão da prevenção na própria prática médica, e a medicina comunitária, que já trazia a questão das comunidades excluídas, marginalizadas, que era o grande debate das ciências sociais no contexto latino-americano da época. Depois o movimento da reforma assumiu um caráter muito mais político, de luta no plano jurídico, pela incorporação dos princípios doutrinários do Sistema Único de Saúde (SUS) na Constituição Brasileira de 1988. Só no final da década de 1980, com a implantação dos Distritos Sanitários, quando Hésio Cordeiro estava na presidência do Inamps, é que se resgatou, a meu ver, um pouco esse foco da mudança do modelo de atenção e se usou a experiência de implantação dos Distritos Sanitários como um espaço de construção de novas práticas. Isso foi importante porque foi o berço da proposta de Vigilância da Saúde, se considerarmos a proposta da Vigilância da Saúde como mudança do modelo assistencial, que vai muito além da Vigilância Epidemiológica, Vigilância Sanitária, Ambiental ou Saúde do Trabalhador...

\section{Revista}

Como nasceu a idéia de usar o termo Vigilância da Saúde para denominar uma proposta de mudança do modelo assistencial?

\section{Carmen Teixeira}

Nasceu exatamente da confluência de três elementos, fato que ocorreu por uma dessas coincidências históricas absolutamente inexplicáveis. Primeiro, a experiência de construção dos Distritos Sanitários, que tinha ligação com o movimento pelos Sistemas Locais de Saúde (Silos), difundido pela Organização Pan-Americana da Saúde (Opas) em todo o contexto latino-americano. Não era uma coisa nossa, na verdade foi um movimento internacional. A Opas estava buscando estratégias para garantir a saúde para todos no ano 2000. Alma-Ata tinha acontecido em 1978 e, dez anos depois, esses organismos internacionais de saúde (OMS/Opas) avaliavam que os países não seriam capazes de alcançar a Saúde para Todos no ano 2000 se não buscassem estratégias de reorganização dos sistemas de saúde. A estratégia que a OMS/Opas aprovou em resoluções foi exatamente a de apoiar a constituição de sistemas locais, que, do ponto de vista do planejamento, retomava o próprio método Cendes. Na publicação Administração estratégica em Silos (Organización Panamericana de la Salud, Washington, D.C., 1992, 159 p.) há uma introdução em que se faz alusão ao Método Cendes e ao Silos, então é como se fossem trinta anos de desenvolvimento conceitual e metodológico na área de planejamento, que partia da programação local (Cendes-OPS) e retornava ao local como base territorial da organização dos sistemas. É como se fosse um grande percurso, uma curva no tempo, em que se partia do local como um espaço de reorganização de serviços na década de 1960 e se voltava 30 anos depois, ao mesmo lugar, para pensar no local de forma renovada. O movimento pelo Silos teve esse momento, essa importância muito grande.

Quanto ao segundo, existia uma discussão sobre planejamento em saúde, e principalmente em planejamento situacional, porque nesse período já se consolidava a difusão das idéias do Carlos Matus entre nós. O Matus escreveu o livro Estratégia e plano no final da década de 1970, livro que começou a ser mais difundido exatamente nesse período (final dos anos 80), quando ele foi inclusive convidado pela Opas para trabalhar como consultor, na época em que escreveu o livro Politica, planejamento e governo. Todos nós que trabalhávamos com planejamento, com o Arouca como professor, começá- 
vamos a nos encantar com a perspectiva situacional, até porque essa concepção se aplica perfeitamente à saúde porque trata de introduzir a noção de complexidade na abordagem dos problemas de saúde, rompendo com a perspectiva anterior, centrada no estudo das doenças, o que se traduzia, em termos de práticas, na Vigilância Epidemiológica de riscos e danos. Ao adotarmos a noção de análise de situação de saúde, o objeto da Vigilância passava a ser a situação de saúde em sua complexidade, resultado da interação entre problemas de saúde e seus determinantes. Tínhamos que pensar a situação de saúde como uma coisa complexa, mas que podia ser analisada, identificada, monitorada e que podia ser o objeto de intervenção a partir da mudança das práticas. Então, do ponto de vista da fundamentação conceitual, conflui aí a discussão de território da Geografia Crítica, entendido como um espaço em transformação e a contribuição da epidemiologia social, que avançava para a análise dos determinantes da saúde. Nesse aspecto, não se pode esquecer o papel do Pedro Luis Castellanos, que nessa época começou a trabalhar também com análise de situação de saúde, tendo publicado um artigo, se não me engano na Revista do CESS, de Rosário, Argentina, em 1987, sobre situação de saúde, assumindo a enfoque situacional. Então, havia esse segundo elemento, que seria o dos conceitos, da construção desse novo paradigma que nos facilitava pensar as práticas de saúde como uma prática de Vigilância propriamente dita.

O terceiro elemento era a discussão de processo de trabalho, que é uma coisa nossa. Ricardo Bruno Mendes Gonçalves tinha publicado a tese dele de mestrado em 1979 sobre processo de trabalho em saúde, ou seja, tinha feito uma análise aprofundada do processo de trabalho médico, de suas raízes estruturais. Ricardo nos deu mais um dos elementos que deveriam ser remontados. Tínhamos o cenário, que eram os sistemas locais; tínhamos mais ou menos a idéia do que queríamos fazer: vigiar situações de saúde, intervir sobre situações de saúde complexas, não apenas sobre doenças específicas, ao mesmo tempo, enfim, tínhamos os elementos, as peças do quebra-cabeça que deveriam ser remontadas - as concepções sobre o processo e trabalho em saúde. Era preciso formar novos sujeitos, pensar novos objetos, mudar as relações de processo de trabalho. Sem Ricardo Bruno, não conseguiríamos pensar a Vigilância; sem o avanço do planejamento da Epidemiologia Social e da Geografia Crítica, não conseguiríamos pensar a Vigilância. Ou seja, tínhamos como pensar e tínhamos a demanda concreta do pensar, que era exatamente o movimento de implantação dos distritos sanitários. Estes não podiam ser apenas um espaço de reforma da assistência médica, como alguns até pensavam na época. Quando juntamos os antigos serviços do Inamps com os serviços das secretarias de saúde, a demanda explodiu, porque todo mundo era cidadão, todo mundo podia ter acesso, as filas aumentaram, e algumas forças políticas e mesmo a população poderiam pensar que, de repente, o Distrito Sanitário se transformava em um imenso pronto atendimento (PA). Foi exatamente aí que dissemos: Não! A Reforma Sanitária não pode ser simplesmente a garantia do acesso à assistência médica ou tão-somente uma organização da oferta para dar conta dessa demanda espontânea. É um espaço de mudança do modelo. E para onde, em que direção? Foi o começo da discussão sobre a integralidade, a equidade e a universalidade. A universalidade de quê? A integralidade de que, de que práticas? Aparece aí toda a discussão da promoção, da prevenção, da assistência e da reabilitação. Foram se juntando os elementos que permitiram a Jairnilson Paim e a Eugênio Vilaça elaborarem os primeiros conceitos de Vigilância. É interessante notar que são conceitos diferentes, mas se complementam. Jairnilson mostra-se muito mais voltado para a idéia de Vigilância como uma mudança na organização do processo de trabalho, porque estava usando o conceito de modo de organização tecnológica do processo de trabalho do Ricardo, e o Eugênio aparece muito mais influenciado pela Opas, até por ser de lá naquele momento, pensando a Vigilância como um modelo de reorganização dos serviços, que implicavam a construção de um sistema local que implementasse práticas de promoção e também descentralizasse as práticas de prevenção, incluindo Vigilância Epidemiológica, Sanitária, Ambiental e Saúde do Trabalhador em função dos territórios, domicílios, áreas de abrangência etc., além de garantir a atenção individual e a própria referência e contra-referência de pacientes. Na época, não se falava tanto 
de organização de redes de atenção, nem de definição de linhas de cuidado, como hoje em dia, mas já se discutia a conformação de redes ou sistemas de referência e contra-referência de pacientes e de informação, que permitissem a integralidade do cuidado.

\section{Revista}

Como uma proposta contra-hegemônica pode quebrar os recortes de poder cristalizados por algumas ações de serviços na busca da integralidade e da equidade e como é possível construir essa mudança paradigmática a partir do currículo?

\section{Carmen Teixeira}

Primeiro, é preciso pensar o que significa dizer que a proposta de Vigilância é contra-hegemônica. Temos novamente que lembrar que estamos em países capitalistas e a grande diferença é que todas as propostas alternativas recusam a idéia de que saúde seja uma mercadoria ou alguma coisa que possa ser comprada, traduzida na compra de algum medicamento ou alguma terapêutica, por mais alternativa que ela possa parecer. Enquanto vivermos em sociedades em que a saúde seja vista dessa maneira, vamos ter que manter essa luta, embora se saiba que mesmo nas sociedades capitalistas é possível fazer com que saúde seja mais do que uma mercadoria, ou não só uma mercadoria, que seja assumida como um direito. Em seu novo filme, Michael Moore faz o papel de um americano perplexo, quando se dá conta de como o país dele é extremamente cruel com seus próprios cidadãos. Isso é interessantíssimo, a postura dele no filme todo é de uma pessoa que está abismada pelo fato de que em outros países se consegue ter um sistema universal, como na França, na Inglaterra e em Cuba. Enfim, o importante é admitir que é possível, mesmo num país capitalista, existir um sistema de saúde que proteja as pessoas, que procure cuidar das pessoas. Quer dizer, é possível pensar que o Brasil, apesar de ser um país de terceiro mundo, da periferia, pobre, pode, sim, ter um sistema de saúde generoso para seus cidadãos, pode ser inclusivo, universal. Claro que vamos discutir o que deve ser universal, incluída a discussão da Vigilância, como não é possível universalizar a assistência médica, não é desejável universalizar a assistência médica hospitalocêntrica e curativa, até porque ela não dá conta da problemática de saúde. Está embutida aí uma crítica à ineficácia do sistema médico hospitalocêntrico, pois quando se pensa em integralidade com prevenção e promoção da saúde é porque se sabe que a situação de saúde, os perfis epidemiológicos, fruto do aumento da expectativa de vida ao nascer, da prevalência das doenças crônicas degenerativas, da violência, nada disso pode ser resolvido a contento apenas com a reprodução do modelo médico hospitalocêntrico. Precisamos investir em promoção da saúde, porque para atuar sobre os determinantes da situação de saúde não temos outra coisa a fazer a não ser buscar uma perspectiva intersetorial na formulação e implementação de políticas públicas voltadas à melhoria das condições de vida dos diversos grupos da população, ao tempo em que se avança com a consolidação das práticas de proteção de grupos vulneráveis, e assistência a pessoas que apresentem problemas considerados prioritários.

Quanto ao currículo, ele é parte de um projeto político pedagógico de formação de sujeitos. Todas as universidades, todos os cursos, em qualquer nível, têm o seu. Muitas vezes, o currículo reflete as tensões entre projetos diferentes. O currículo de uma faculdade de medicina, por exemplo, projeta a permanência de uma perspectiva médico-assistencialista, clínica, que é necessária, mas cada vez menos suficiente para se ter um impacto positivo sobre as situações de saúde da população. Então, precisamos mudar o currículo. Mas essa mudança enfrenta uma série de limitações. Primeiro, os professores, em geral, resistem à mudança este é o problema das faculdades de medicina. Às vezes, faz-se uma reforma de currículo, mas os professores são os mesmos, reproduzem em suas práticas todos os valores que o novo currículo tenta negar. Segundo, a própria formação em si; por melhor que seja, o perfil do egresso se materializa de fato é na prática, conforme analisa Marília Fontoura em sua recente tese de doutorado. Marília estudou os egressos dos cursos de especialização em Saúde da Família. A pergunta era até que ponto esses egressos usavam ou não os conteúdos, as técnicas, os métodos que aprenderam no curso, no qual o currículo foi todo desenhado segundo o enfoque por competências, os conteúdos foram trabalhados no formato modular, e as práticas 
pedagógicas enfatizaram a problematização. A pergunta central do estudo era se os egressos usavam os conhecimentos e habilidades adquiridas na prática cotidiana, nas equipes de saúde da família nos municípios, e a maioria não usa. Chegam nos municípios e encontram um gestor que, muitas vezes, entende o Saúde da Família como apenas um programa expansionista de atenção simplificada e primitiva para a população pobre da periferia do município, não entende o Saúde da Família com aquela perspectiva da Vigilância que tentamos trabalhar, com planejamento e programação local, identificação de problemas na base territorial, um trabalho multiprofissional que começa na casa, no domicílio, com o agente comunitário. Enfim, hoje, o próprio Saúde da Família como espaço de reorganização da atenção básica é, também, um espaço de tensão entre os modelos: o modelo assistencial, do PA, do atendimento à demanda espontânea; e o modelo de atenção integral, fundado na concepção da Vigilância. Marília mostra em sua tese que a formação ajuda, mas não é suficiente para a mudança das práticas. Se o egresso não encontra condições de gestão do processo de trabalho favoráveis à utilização dos conteúdos, métodos e técnicas que estudou durante o curso, sua prática cotidiana tende a reproduzir o modelo que se quer transformar.

\section{Revista}

Qual seria então o lugar da subjetividade na formação de profissionais da saúde? Como expressá-la no currículo?

\section{Carmen Teixeira}

Comecei a me interessar pelo tema 'subjetividade em saúde' a partir de uma crítica que o Emerson Merhy nos fez, na área de planejamento. É conhecida. Ele disse que nós, que trabalhamos com a noção de Vigilância, somos higienistas, estamos preocupados é com a questão de contar os óbitos. Isso me deixou 'mordida' na época porque percebi que, ao relatarmos nossas experiências de trabalho nos distritos sanitários, ao sistematizarmos os esforços que desenvolvemos para produzir uma articulação de conceitos e metodologias de trabalho que nos ajudassem a operacionalizar os princípios que defendíamos com relação à reforma do modelo de atenção, não escrevemos sobre a dimensão das relações, da constituição de su- jeitos, na prática. Embora a questão do outro nunca tenha deixado de ser parte da nossa preocupação, do cuidado, da atenção no sentido pleno da palavra, quando falamos de modelo de atenção, concordo que o grupo de Campinas, mais especificamente o Emerson, tem razão: nós nunca tematizamos nem escrevemos sobre isso. Estimulada pela crítica, decidi estudar a produção do grupo de Campinas para entender os caminhos que eles haviam percorrido e os autores que tinham lido para pensar exatamente essa questão, a questão do sujeito. Cheguei a montar até um curso, intitulado Planejamento e subjetividade, oferecido como disciplina optativa em nosso programa de pós-graduação. Foi muito bom porque pude perceber como, por exemplo, alguns integrantes do grupo estavam trabalhando com autores provindos do campo da psicanálise, como a Rosana Onocko trabalha e o próprio Gastão Wagner. Mas decidimos não caminhar por aí. É interessante conhecer o caminho percorrido por outros autores, mas, no nosso caso, acho que devemos trilhar mais os caminhos da ética do que os da psicanálise. Nossa opção é mais próxima do que a Lilia Blima Schraiber apontou em um texto onde problematiza a área de Planejamento, Gestão e Avaliação em Saúde (Ciência e Saúde Coletiva, v. 4, n. 2, p. 221-241, 1999). Lilia chamou atenção para a importância da dimensão ética embutida nas relações sociais no campo da saúde, como de resto em qualquer relação social, ampliando e redefinindo a preocupação que temos, desde os primórdios da Saúde Coletiva, com a dimensão técnica e a dimensão política do trabalho em saúde. Falamos da dimensão ética sempre como uma questão do humanismo, que no fundo recupera a atenção ao outro, algo presente no humanismo médico tradicional, da humanização da relação médico-paciente, mas não se trata somente disto, estou querendo pensar a questão da ética mais a partir da Hannah Arendt, como amor ao mundo, analisado, por exemplo, no livro Ética e política em Hannah Arendt. Acho que vamos ter de trabalhar isso nos currículos, lembrar para os nossos alunos que o trabalho em saúde não é só instrumental - onde já avançamos -, não é só o aprendizado de conhecimento, de métodos, de técnicas para intervir sobre um determinado objeto. É também uma ação comunicativa. Precisamos aprender a dialogar, a trabalhar em equipe. 
Além disso, além de aprender a técnica, ou seja, a usar instrumentos e a conversar, precisamos ter valores que são nossos, que devemos incorporar, para ressignificar o nosso lugar no mundo, o sentido das escolhas que fazemos, profissionais, políticas, existenciais, de um modo geral. No fundo, é algo que me faz lembrar de uma canção de Eduardo Dussek: 'Pare o mundo que eu quero descer'. De fato, refiro-me a um sentimento, uma constatação de que se o mundo continuar nessa direção, eu não quero ir. Por isso, temos que fazer alguma coisa para mudar a direção, e essa é uma responsabilidade de todos que vivem essa angústia, essa perplexidade, esse desejo e essa esperança de contribuir para a construção de um mundo melhor. E não é só no sentido da militância política. Sem dúvida, muito do que fizemos e fazemos é por uma questão de militância, por uma utopia revolucionária. Mas não é só disso que estou falando: a luta pela saúde ultrapassa a revolução. É mais no sentido em que o Arouca pregava, quando dizia que a Reforma Sanitária é um projeto civilizatório, portanto não se trata simplesmente de fazer revolução, mas de criar um mundo melhor, uma outra racionalidade, uma outra forma de viver, o reencantamento por estarmos vivos, sermos o que somos, pensarmos, trabalharmos, amarmos. Pode parecer poesia o que estou falando, mas não é à toa que estou lendo mais poesia do que saúde pública ultimamente. Talvez porque eu esteja ficando velha, ou porque meu tempo esteja ficando curto, ou ainda porque eu tenha a pretensão de deixar alguma coisa escrita para que meu filho, ou meus netos amanhã, quando lerem, sintam orgulho de mim, ou meus alunos, que dirão assim: ela foi uma sonhadora. Mas é importante que alguém sonhe de vez em quando, já trabalhamos muito e temos que continuar a sonhar, enfim.

\section{Revista}

Com o foco em formação de currículo, como agregar a proposta da promoção da saúde sobre empoderamento da população e dos sujeitos que cuidam - em vez de culpar o indivíduo, ele é chamado a fazer parte de um corpo coletivo como agente de mudança - no âmbito do SUS?

\section{Carmen Teixeira}

A pergunta me faz lembrar da tese de Maria Caputo, exatamente sobre promoção da saúde.
Ela trabalha muito essa categoria do empoderamento e a discute não apenas em sua acepção política, coletiva, social, mas também no plano psicológico, individual. Na dimensão do coletivo, empoderamento indica a capacidade de mobilização, de organização, de ação, de luta pelos direitos, por mudanças nas condições de vida e trabalho. Na dimensão individual, empoderamento tem a ver com a formação dos sujeitos, em um processo de autovalorização, de aumento de sua auto-estima. Por exemplo, quando o pessoal do Proformar trabalha com aqueles livros bonitos, coloridos, bem-feitos, eles se sentem valorizados, pois estão trabalhando com um material que foi bem cuidado, bem produzido, o que repercute na significação que poderão dar ao trabalho que vão realizar. Isso terá que ser incorporado ao currículo, não sei exatamente como, mas você já está apontando: temos que valorizar, fazer com que as pessoas valorizem de novo aquilo que estão fazendo, por mais simples que seja, o que só ocorre quando percebemos a contribuição que o nosso trabalho, mesmo pequenininho, dá ao processo coletivo. Isso é superar a alienação, se voltarmos ao conceito de alienação, como visto pelo velho Marx. O que é o trabalho alienado? O trabalhador alienado é exatamente aquele que não tem idéia da contribuição que está dando ao conjunto, que repete mecanicamente, que reproduz tarefas parcelares sem apreender o conjunto do processo de produção. Então, uma forma de superar a alienação é fazer com que cada um perceba o lugar que ocupa num determinado contexto. Portanto, é preciso incorporar nos currículos o aprendizado de análises de contexto, o que só pode ocorrer quando os sujeitos começam a valorizar a história. A história de cada um tem que ser recuperada para as pessoas entenderem como chegaram ali, bem como a história do coletivo. Como chegamos aqui? O que é a Reforma Sanitária? O que é o Brasil? Como é que pensamos o Brasil, o sistema de saúde brasileiro? Jairnilson Paim está trabalhando, atualmente, em sua a tese sobre a Reforma Sanitária. Ele recuperou todo o processo histórico dos fatos que configuraram a conjuntura pré e pós-constituinte, partindo do pressuposto de que a Reforma Sanitária fez promessas que não cumpriu. No percurso de construção da tese, Paim começou a reler vários sociólogos e cientistas políticos que pensaram o Brasil, como 
Sérgio Buarque de Holanda, Florestan Fernandes, Caio Prado Junior, Fernando Henrique Cardoso e outros sociólogos e cientistas políticos. Foi desta forma que a pergunta de Paim passou a ser: 'Como se insere esse movimento pela reforma sanitária num pensamento sobre o Brasil?' Esse é um exemplo de um esforço intelectual que nos ajudará a refletir sobre o lugar que ocupamos no processo coletivo e sobre os efeitos que este processo coletivo produziu na vida de cada um de nós. Concluindo, penso que as pessoas deixam de ser alienadas quando se dão conta do lugar que ocupam na história e, portanto, precisamos estimular, em cada um dos nossos cursos, a realização desse movimento, dessa reflexão crítica sobre si mesmo e sobre o processo histórico que nos coube viver.

\section{Revista}

Como trabalhar e ver os próprios propósitos de mudança diante de um cenário marcado por uma lógica normativa? Qual o alcance do trabalhador de alterar as práticas, se o que se vê é ainda o aprisionamento de uma pré-programação das PPI, as Programações Pactuadas Integradas?

\section{Carmen Teixeira}

Creio que vamos ter que trabalhar com esta tensão ainda por muito tempo, até por conta do que falávamos antes quanto à globalização e à complexificação da situação de saúde. Não tenho nada contra as normas. Aliás, concordo com Carlos Matus, que diz que o momento normativo faz parte do processo de planejamento. A questão é que as normas, às vezes, são vistas como uma camisa-de-força, as pessoas lêem os pactos como se fosse para fazer aquilo e pronto, estou fazendo o que o Ministério mandou. No fundo, não é um problema da norma, mas da cultura organizacional, que é herdeira de um passado marcado pela centralização. As pessoas não acreditam que têm autonomia de pensar, de inventar, de criar. Pensam que é muito mais fácil obedecer do que se arriscar a fazer uma coisa nova que pode não dar certo. Nosso sistema ainda tem esse problema. E digo isso porque trabalho com o município. Quando começamos a fazer planejamento, há sempre uma dúvida. Pode isso? Além do mais, significa sempre mais trabalho você fazer alguma coisa nova. No princípio, sempre soa como mais trabalho, o que também é parte da nossa cultura não gostarmos muito de trabalhar. Portanto, é um problema cultural, de cultura organizacional. Primeiro, a questão da centralização; segundo, a não valorização do trabalho. Então, a lógica é 'vamos trabalhar o mínimo possível, fazer o que me pedem, o que estão pagando. Para que vou querer mais, se não tem ninguém valorizando?' Então temos que trabalhar essa questão no âmbito dos cursos, romper com essa cultura do não trabalho, ou do que chamamos no Instituto de Saúde Coletiva de 'o mínimo legal'. Não, vamos tentar fazer com que as pessoas, os gestores, os trabalhadores se dêem conta de que é prazeroso inovar, inventar, criar; desenvolver a autonomia, a criatividade, a possibilidade de fazer diferente.

Em Salvador, quando fomos trabalhar no plano municipal de saúde, além de todas as coisas comuns, como a organização da atenção básica, a promoção da saúde, a Vigilância, nos deparamos com a grande novidade que foi a demanda da população pela formulação de uma política de saúde da população negra. Havia um grupo com liderança e poder de pressão que acabou se institucionalizando como um grupo de saúde da população negra. Com isso, o planejamento teve que absorvê-lo, porque existia um movimento anterior de construção da autonomia do problema. Eis aí um tema que temos de introduzir nos cursos, nos currículos, porque é fácil dizer que as pessoas devem ser criativas, mas dificilmente as pessoas são espontaneamente criativas, para romper com essa cultura organizacional do não trabalho, do mínimo legal, do obedecer, do centralizado, do não inventar, do não inovar. Temos que identificar e formar lideranças, discutir a questão da liderança, e o Javier Uribe, da Escola Nacional de Saúde Pública Sergio Arouca (Ensp), está trabalhando muito com o tema no livro de sua autoria Gestão pela escuta. Ele é uma pessoa preciosa nessa questão, porque está recuperando a discussão da obra $A$ dança das mudanças, de Peter Senge, e trazendo o conceito do líder jardineiro, que deve ser incorporado nos cursos. Posso ter num município pessoas com condições de exercer o papel de jardineiros, de identificar as pessoas que podem ser plantinhas que vão construir um novo jardim. A idéia é interessante. Tem gente que naturalmente é líder. Você vê uma meninada jogando bola, tem logo 
aquele que grita, o Dunga do time. Hoje, o pessoal que trabalha com liderança diz que há pessoas que, por uma questão de temperamento, de personalidade, tem naturalmente esta tendência de exercer uma certa liderança, organizar o processo coletivo de trabalho, exercer este papel de dirigente, mas a liderança pode ser cultivada. Uma pessoa que é tímida pode, ao longo da vida, superar a timidez. Existem técnicas para se superar a timidez, para aprender a ser líder, um negociador ou um organizador do trabalho coletivo; aprender a estimular as pessoas, a motivá-las. Na minha opinião, essa temática deve ser enfrentada em todos os cursos na área de saúde pública, porque estamos falando de mudança, e não apenas de treinar ou capacitar pessoas para reproduzir o que já se faz, mas como mudar. Não se trata apenas do líder heróico, o líder que vai à frente e a equipe técnica e os trabalhadores seguem atrás. Estamos habituados a seguir esse tipo de líder, pessoas excepcionais que dão o exemplo e nos sentimos orgulhosos de acompanhá-los. Contudo, precisamos cada vez menos de líderes heróicos. Necessitamos, sim, de líderes jardineiros, que estão ali no cotidiano, que aparecem pouco, mas são aqueles que estão todo dia regando, plantando, semeando, propiciando uma mudança mais molecular.

\section{Revista}

Gostaríamos que comentasse sobre os aspectos da intersetorialidade que podem contribuir para a efetividade e a integralidade das ações na perspectiva da melhoria de qualidade de vida das coletividades.

\section{Carmen Teixeira}

Vivi duas experiências que me ajudaram a pensar essa questão. Quando estávamos elaborando o plano de promoção da paz e combate à violência em Salvador, os alunos do curso não eram todos da área da saúde. Havia pessoal de todas as secretarias do município. Assim, eu tinha nas mãos uma equipe heterogênea, com formações completamente diferentes, das áreas de engenharia, segurança, educação, saúde, ciência e tecnologia. Nosso primeiro desafio foi construir um consenso em torno de alguns conceitos, o chamado alinhamento conceitual. Portanto, estávamos construindo a possibilidade de uma política intersetorial a partir de pessoas de di- versos setores. Aprendi que quando se trabalha no plano político, na formulação de propostas de intervenção sobre problemas de saúde, o primeiro desafio é a construção do consenso em relação à pertinência de uma política que tenha como objeto os determinantes da saúde, que não se concentre em intervir os efeitos, mas que trabalhe com os determinantes. Agora, é diferente trabalhar a intersetorialidade com pessoas da área de saúde, pensando no desenvolvimento de sua capacidade de aglutinar, motivar, mobilizar pessoas de outros setores no âmbito do território municipal. Aí a minha experiência já é diferente. Tomo como exemplo um trabalho recente que tive a oportunidade de fazer no município de Camaçari, na Bahia. O prefeito convidou um grupo de pessoas das diversas áreas para formular, conjuntamente, um plano estratégico para o desenvolvimento do município, porque não estava satisfeito com os planos que cada setor apresentou. Ele preferiu que fizéssemos uma outra leitura da informação, que identificássemos os problemas e populações-problema, e pensássemos uma ação intersetorial, com a concentração de esforços em um determinado grupo da população pobre da cidade. No fundo, ele reproduzia a idéia de focalização, mas não era só com a saúde, e sim com outras áreas também. Esses exemplos ilustram duas estratégias totalmente diferentes, tanto no momento da formulação quanto no da organização da intervenção, mas as duas têm um mesmo objetivo: atuar sobre determinantes, melhorar a qualidade de vida.

\section{Revista}

Na perspectiva dos trabalhadores de saúde, em particular os de nível médio, diante das dificuldades de se trabalhar com intersetorialidade, empoderamento e promoção da saúde, como falar de uma categoria profissional ou de diferentes categorias articuladas em torno de um agir com base territorial fundamentada na concepção de vigilância em saúde?

\section{Carmen Teixeira}

Essa é uma discussão mais ampla também, porque tem a ver com a questão do perfil profissional do sanitarista. Já se pensou em reformular sua formação, com a criação de um curso de graduação em saúde coletiva, mas no próprio campo não há consenso em relação a 
essa idéia. Criar um curso de graduação em saúde coletiva é um passo à frente na nossa distinção com relação aos médicos, enfermeiros, ou seja, um elemento a mais da luta contrahegemônica pela construção do novo modelo de atenção. A evolução conceitual, metodológica, instrumental do campo da saúde coletiva demanda um profissional em saúde coletiva, e para nós ele não é o antigo sanitarista, formado em um curso de especialização. Para nós, o novo sanitarista será um profissional graduado em saúde coletiva. Poderíamos pensar também no nível médio. Acho muito interessante a proposta de vocês porque a meu ver se articula com a nossa discussão sobre as competências do profissional do campo da saúde coletiva, quais sejam: a de vigilância, como pensamos a vigilância da saúde, que é o que vocês estão que-rendo exatamente especificar para o nível médio; a de gestor do processo de trabalho coletivo, uma pessoa que tenha capacitação gerencial, que seria hoje o que a enfermeira da saúde da família faz, isto é, planejamento do processo de trabalho das equipes; e, por último, a de comunicador social em saúde, alguém que faz a interface da promoção com os movimentos sociais, que é o que pensávamos do agente comunitário, um novo educador sanitário, promotor da consciência de cidadania, mobilizador dos processos de controle social, formador da consciência acerca dos direitos e, ao mesmo tempo, uma 'ponte' com a equipe de saúde da família para o encaminhamento da solução dos problemas de saúde individuais e coletivos. Essas idéias estão presentes em alguns debates sobre o papel dos agentes comunitários, logo no início do processo de implantação da Saúde da Família, depois se perdeu, porque o modelo hegemônico absorve e acaba transformando o agente comunitário num 'minimédico', como uma auxiliar de enfermagem vira uma 'minienfermeira', quer dizer, a força do modelo hegemônico é exatamente essa: subverter todas estas propostas de mudança que tentamos implementar, porque as próprias pessoas, depois que fazem o curso de capacitação do agente comunitário, se aproximam do modelo hegemônico e passam a querer ser o 'médico', o agente de saúde que vai na casa das pessoas reproduzir a concepção e as práticas tradicionais.

\section{Revista}

Ainda com base na pergunta anterior, discutese a idéia de o agente local de vigilância ter uma identidade para atuar. Não seria um avanço a criação de uma categoria profissional de trabalhadores da vigilância em saúde?

\section{Carmen Teixeira}

Eu tendo a achar que é vantagem construirmos a categoria profissional do vigilante da saúde. $\mathrm{Na}$ verdade, estamos falando de construção de novas identidades profissionais na área de saúde, melhor dizendo, identidade pós-profissionais. Nós, do Instituto de Saúde Coletiva, quando discutimos a universidade nova, defendemos a criação de um bacharelado em saúde, diluindo em princípio as categorias profissionais antigas, propondo que todos os interessados em vir a trabalhar na área de saúde tenham uma formação básica comum, que inclui, além de conhecimentos científicos e tecnologias específicas da área da saúde, a abertura para as humanidades, a arte e a filosofia, levando em conta a contribuição que este tipo de aprendizado pode vir a ter para o desenvolvimento da sensibilidade e da consciência crítica necessária para se lidar com a complexidade que a questão da saúde assume no mundo hoje. Na verdade, o que está sendo colocado é exatamente a proposta de se constituir uma formação básica num determinado campo de saber, que seria o da saúde, com toda a complexidade inerente ao campo, e depois a opção pela profissionalização, que ocorreria já no quarto ano do bacharelado. Com isso, superamos a falsa polêmica entre a formação de profissionais 'gerais' e 'especializados', como por exemplo, a discussão entre a formação do médico generalista e/ou o especialista. Tem-se uma formação geral em saúde que é terminal, podendo não implicar, inclusive, numa profissionalização posterior. Considerando, entretanto, que o mercado exige identidade profissional, há que se ter uma formação geral e, ao mesmo tempo, batalhar pela profissionalização. Retomando o exemplo dos profissionais da Vigilância, penso que sua formação faz parte da estratégia contra-hegemônica, na medida em que eles vão se constituir, amanhã ou depois, naqueles que se mobilizarão pela manutenção e ampliação das práticas de Vigilância da Saúde no SUS e para muito além dele. 


\section{Nota}

1 Entrevista concedida a Mauricio Monken, Gracia Maria de Miranda Gondim e Carlos Eduardo Colpo Batistella, respectivamente coordenador e professores-pesquisadores do Laboratório de Educação Profissional em Vigilância em Saúde (Lavsa), da Escola Politécnica de Saúde Joaquim Venâncio/Fiocruz. Sérgio Renato Torres Júnior, bolsista PEC, colaborou na transcrição. 